\title{
TITULARES DE ACTOS DE HABLA EN LA PRENSA HISPANA CON EL ORDEN DECLARACIÓN - DECLARANTE
}

\author{
SILVIA HuRTAdo GONZÁLEZ \\ Universidad de Valladolid \\ silvia@fyl.uva.es
}

\begin{abstract}
Resumen
En este trabajo se analizan los titulares de actos de habla cuyo locutor originario aparece mencionado tras la cita. Los datos provienen de la lectura, en 2010, de diferentes diarios digitales españoles e hispanoamericanos. Es nuestra intención demostrar que esta forma de transmisión informativa de las declaraciones está muy alejada de la objetividad a la que se supone que deben aspirar los periodistas, en el sentido de que la selección léxica del verbo de lengua, la manera de aludir al autor de la cita y, por supuesto, la posición focal del rema pueden servir para orientar ideológicamente la noticia.
\end{abstract}

PALABRAS CLAVE: titulares, discurso referido, discurso periodístico, prensa hispanoamericana, prensa española.

\begin{abstract}
This investigation analyses the headings of speech acts whose original announcer is mentioned after the quote. The data come from reading several Latin American and Spanish digital newspapers in 2010. Our goal is to show that this form of information transmission encountered in declarations is far away from the objectivity journalists are supposed to represent. Different ways of ideologically orienting the news are the lexical selection of the verb, the form of mentioning an author in a quote and, obviously, the focal position of the rhema.
\end{abstract}

KEYWORDS: headings, reported speech, press discourse, Latin American press, Spanish press

\section{Introducción}

\subsection{Sobre los titulares}

El titular ${ }^{1}$ es el elemento fundamental de cualquier información, por lo que representa la expresión del más alto nivel de la macroestructura informativa. Por esta

\footnotetext{
${ }^{1}$ No hay que confundir titular con título. El término título hace referencia al elemento fundamental del titular, mientras que titular incluye al título, pero no exclusivamente, porque este puede ir acompañado por otros elementos. Ahora bien, cuando el titular solo contiene un elemento -el título- puede afirmarse que ambos términos son sinónimos. Precisamente porque, en ocasiones, el encabezado lo ocupa solo el título, ambos términos parecen ser la misma cosa. Dado que en el corpus analizado, procedente de la prensa digital, el encabezado, por lo general, consta de una sola secuencia lingüística, en este trabajo se utilizan los dos términos indistintamente.
} 
razón, debe servir de estímulo y llamar la atención para suscitar el interés por el cuerpo de la noticia. En la medida en que se trata de un resumen, funciona como un texto autónomo del cuerpo mismo de la información.

Dicha secuencia lingüística ha sido desde siempre un elemento clave del texto periodístico, y esta importancia no ha hecho sino acentuarse con el advenimiento del ciberperiodismo. En los medios tradicionales, los titulares han venido cumpliendo tres funciones: función identificativa (sirven como recurso para individualizar un texto periodístico frente a otros), función informativa (sintetizan el contenido del texto periodístico que encabezan) y función apelativa (pretenden despertar la curiosidad del lector). Pues bien, en los cibermedios los titulares han sumado a las tres anteriores una cuarta función: la hipertextual ${ }^{2}$ (Salaverría, 2005: 80). Esta función permite que los titulares sirvan también para la navegación en los cibermedios, al situar en ellos los enlaces hipertextuales que hacen posible desplegar el texto de la información. Ahora bien, esta ampliación de funciones, privativa de los medios digitales, no ha anulado la división clásica de los títulos periodísticos en dos categorías principales: aquellos que tienen como finalidad principal sintetizar la información (títulos informativos) y aquellos que buscan sobre todo la evocación cuasiliteraria (títulos creativos), aunque, como apunta Salaverría (2005: 83), no se trata de categorías mutuamente excluyentes: los títulos informativos pueden ser creativos hasta cierto punto, y al revés. Si bien para nuestro trabajo esta simple división nos parece suficiente y operativa, establecer una tipología detallada de estas secuencias periodísticas es una tarea ardua y compleja, dado que los titulares, en su relación semiótica con la noticia, son significados cargados de posibilidades de codificación (Gómez Mompart, 1982: 108-109)33.

\footnotetext{
${ }^{2}$ Aunque sin emplear esta denominación, autores como Díaz Noci (2002: 107) también han destacado la presencia de esta función en los titulares periodísticos de Internet.

${ }^{3}$ Existen varias propuestas de clasificación de los titulares, de acuerdo con diferentes perspectivas de análisis. Dos de las propuestas más importantes son las de Alarcos Llorach y Núñez Ladevéze. El modelo de Alarcos Llorach (1977: 144-145) clasifica los titulares de acuerdo con los siguientes parámetros: por su condensación sintáctica, por su estructura nominal, por su expresión lingüística y por su configuración lingüística. Por su parte, Núñez Ladevéze (1991: 221-230) propone una taxonomía híbrida, basada en criterios tanto lingüísticos como estrictamente periodísticos. Al margen de estas clasificaciones, ya clásicas, se han propuesto otras, como la de López Hidalgo (2001: 48-56), que atiende a varias características que tienen que ver con las funciones del lenguaje. Pero la clasificación más detallada y exhaustiva de todas es la propuesta por Zorrilla Barroso (2002), al tomar en consideración cinco parámetros: sintaxis, complejidad, coherencia, referencia y función comunicativa. Sin embargo, pese a las propuestas existentes, y tal como apunta Sánchez García (2010: 42), es arriesgado decantarse por una taxonomía en particular, pues «incluso las clasificaciones más operativas no han quedado más que en intentos, ya que no son modelos exhaustivos, al no contemplar todos los tipos de títulos que podemos encontrar en el diario.»
} 


\subsubsection{Los titulares de actos de habla}

Núñez Ladevéze (1995: 67) distingue dos tipos de titulares informativos: los que enuncian actos de habla de personas de cuyas manifestaciones se informa, y los que se refieren a acontecimientos en los que el contenido principal de la información no es lo que alguien ha dicho, sino las cosas que han ocurrido. En el primer caso, el objeto del título es, en efecto, un acto de habla. En realidad, la mayor parte de las noticias, incluyendo la titulación, se origina en declaraciones o procesos de habla (Bell, 1991; Núñez Ladevéze, 1991; Fairclough 1995; Waugh, 1995; Nadal Palazón, 20094, entre otros), lo que se debe, por un lado, a que los periodistas frecuentemente escriben sobre acontecimientos que no han presenciado (Waugh, 1995) y, por otro, a que buscan otorgar credibilidad a la noticia al referir declaraciones (Van Dijk, 1990; Rodrigo, 1989; Waugh, 1995 y Romero, 2000). En esta situación, lo que se traslada al texto son las palabras ajenas, circunstancia que permite que el periodista escoja para su transmisión entre algunas de las múltiples alternativas que le ofrece la lengua.

Resulta necesario detenerse para definir los términos que aquí serán empleados. En este trabajo partimos de la noción de discurso referido como:

todo enunciado para cuya comprensión es necesario presuponer la copresencia de dos instancias de enunciación diferentes: el aquí y el ahora del hablante que refiere el periodista y locutor principal - y el aquí y el ahora del hablante referido - las voces y fuentes que acceden a las noticias. (Santander Molina: 2003: 12) ${ }^{5}$

De este modo, el texto periodístico, y muy especialmente los titulares de prensa, se erigen como el espacio en el que convergen dos discursos relacionados con dos tipos de voces: la del emisor (periodista) que reelabora o transmite las declaraciones, y la del actor de los hechos narrados. En otras palabras, de acuerdo con Gutiérrez Ordóñez (1997), nos encontramos aquí con dos tipos de sujetos: el sujeto de la enunciación, que se corresponde con el periodista, en tanto que emisor del texto periodístico, y el sujeto del enunciado (el actante que desempeña la función narrada por el primero). Se llama primaria a la enunciación propia y secundaria, a la ajena; y se denomina habitualmente L1 al locutor de la enunciación primaria y L2, al de la secundaria. En el caso de los titulares de prensa, L2 corresponde a la fuente periodística, es decir, a la persona que produjo una declaración cuyo contenido ha sido considerado de interés noticioso.

\footnotetext{
${ }^{4}$ Para el caso concreto de la prensa mexicana, Nadal Palazón (2009: 24) destaca que aproximadamente el $64 \%$ de las noticias tiene su origen en declaraciones.

${ }^{5}$ Hay que entender el discurso ajeno no solo como las palabras generadas por otro locutor, sino también, por extensión, todo discurso o segmento discursivo que trasluzca, de manera explícita o implícita, la alusión o presencia de una enunciación ajena en la propia. Puesto que se trata de alusión o presencia, quedan comprendidos en esta noción de «discurso ajeno» los términos «discurso referido» y «discurso reproducido» (Nadal Palazón, 2009: 20), que se oponen gracias a la condición de representatividad (Maldonado, 1991: 20).
} 
Precisamente es en el discurso periodístico donde la dinámica existente entre los discursos primarios y secundarios resulta más característica y frecuente; incluso, llega a ser más destacada que en otros registros, como el conversacional o el literario.

Por otro lado, en toda noticia originada por las declaraciones de algún protagonista de la actualidad, las palabras objeto de la información son transformadas por el periodista mediante su reelaboración lingüística. Incluso, el uso discursivo de los titulares ha desarrollado estructuras lingüísticas propias, difícilmente empleadas en otras situaciones de habla. Por lo tanto, el análisis de estos mecanismos para procesar el discurso ajeno en el propio resulta de una importancia crucial para el análisis de los titulares periodísticos, toda vez que la gestión discursiva de las declaraciones ajenas conlleva una enorme responsabilidad.

\subsection{Sobre los objetivos, la metodología y el corpus}

El objetivo de esta investigación es el análisis detallado de un tipo concreto de titular de acto de habla: el titular de acto de habla con el orden declaración - declarante. Esta ordenación, donde la declaración constituye el rema (en términos periodísticos, la noticia) y el declarante es el tema (la fuente periodística que se supone como parte del contexto extraverbal compartido por emisor y receptor), con la que se prefiere conferir mayor importancia focal al presunto enunciado secundario, ha recibido el nombre de «subjetiva enfática» (Mathesius, 1975) frente a la «objetiva normal», con el orden inverso, de la que no nos ocupamos aquí. La elección de uno u otro orden no es fortuita, sino que responde a estrategias discursivas específicas motivadas por patrones ideológicos compartidos por L1 y la organización editorial.

Así pues, el titular de acto de habla con el orden declaración - declarante constituye una forma de transmisión informativa de las declaraciones que está muy alejada de la objetividad a la que se supone que deben aspirar los periodistas, no solo en el sentido de que la posición focal del rema puede servir para orientar la postura ideológica del redactor del titular, como ya hemos adelantado, sino también por la selección léxica del verbo de habla y por la manera de aludir al locutor secundario. No hay que olvidar que el periodismo es un instrumento para la difusión y legitimación de determinadas ideologías, razón por la cual en el lenguaje de la prensa se manifiesta de manera privilegiada el carácter argumentativo del discurso. Esta capacidad argumentativa es acuciante en el caso de la titulación periodística, por tratarse de la parte más importante del texto periodístico.

Sin olvidar la Teoría de la Argumentación de la lengua y sus desarrollos posteriores, integramos en nuestro estudio aportaciones de métodos y teorías diversos presentes en autores como Van Dijk (2003), Fairclough (1995) o Hodge y Kress (1993). Asimismo, hemos tomado como referencia el trabajo de Nadal Palazón (2009) sobre el discurso ajeno en los titulares de prensa mexicana, ya que aborda el problema del discurso ajeno desde las varias perspectivas de análisis polifónico del discurso, pasadas y presentes, y las integra en la medida de lo posible dentro de su modelo o método elaborado a partir 
de un corpus de titulares periodísticos procedentes exclusivamente de la prensa mexicana.

Asimismo, nuestro análisis combina métodos cuantitativos y cualitativos. La descripción estadística tiene como principal finalidad determinar la importancia de la modalidad discursiva en cuestión e identificar tendencias generales del discurso de los titulares así como comportamientos específicos de los diarios considerados, mientras que con el análisis cuantitativo se pretende explicar los diferentes aspectos que comporta el empleo de los titulares que nos interesan y que son objeto de este trabajo.

En cuanto al corpus que supone la base de esta investigación, los datos provienen de la lectura durante catorce días, no consecutivos, en los meses de septiembre y octubre de 2010 de los siguientes diarios digitales: El País y El Mundo (de España), El Tiempo (de Colombia), La República (de Perú), El Universo (de Ecuador), El Universal (de México), El Mercurio (de Chile) y La Nación (de Argentina). Todos ellos pueden considerarse representantes de la llamada "prensa de calidad», término con el que se hace referencia a aquella prensa seria, de un alto nivel cultural, que cuida los textos y que cuenta con gran credibilidad.

\section{Presentación de los resultados}

La expurgación de estos periódicos en su versión electrónica arrojó un total de 228 titulares de actos de habla con el orden «declaración - declarante». Aunque no se trata de un número especialmente significativo, creemos que, dadas las singularidades que presenta, es un tipo de titular digno de atención, lo que justifica su análisis de forma independiente.

Hay que partir del hecho de que esta forma de titulación no se encuentra uniformemente repartida en toda la prensa hispanohablante. Así, mientras que en la prensa mexicana y, especialmente, en la colombiana es posible e, incluso, hasta cierto punto habitual encontrarnos con este tipo de titulación, en el resto de los periódicos analizados su presencia es escasa o inexistente, como veremos enseguida.

Al margen de esta circunstancia, existen dos posibilidades para la formación de estos títulos: con verbo de habla expreso o con verbo de habla elidido. En ambos casos la cita en cuestión suele ir acompañada de índices gráficos (muy frecuentemente, comillas simples en la prensa hispanoamericana), pero no es un requisito que se cumpla siempre. Por otra parte, esta marca (comillas simples o comillas dobles) puede afectar a todo el enunciado secundario o solo a algún constituyente de este.

\subsection{Titulares del tipo «declaración - declarante» con verbo de habla expreso}

De los dos tipos señalados, el más frecuente en nuestro corpus es el primero, cuyo esquema es «declaración - signo de puntuación - verbo de habla - autor de la declaración o declarante». Es decir, el periodista opera seleccionando parte de las declaraciones del protagonista de la noticia, pero en este caso las sitúa delante del verbo 
seguido del sujeto. En estos titulares con verbo de habla expreso en los que el enunciado primario sucede al secundario es la coma, por lo general, la que indica gráficamente la yuxtaposición.

De los 228 títulos consignados, 118 siguen este patrón, lo que porcentualmente supone el $51,8 \%$. Sin embargo, como ya se ha adelantado, este tipo de titular no es empleado en la misma proporción por todos los periódicos de habla hispana. En el estudio mencionado de Nadal Palazón (2009: 40), se señala que la estructura con el orden señalado anteriormente es mayoritaria en la prensa mexicana; concretamente, dicha colocación supone, según sus datos, el 98,2 \% del total de titulares con verbo de lengua subordinante expreso. Frente a esto, lo que se observa en nuestro estudio comparativo es que la mayoría de los casos pertenecientes a este grupo de titulares procede de El Tiempo, periódico elegido como representante de la prensa colombiana. En efecto, 91 de los 118 titulares pertenecientes a dicho grupo han sido extraídos del diario colombiano. Le sigue la prensa argentina con 13 casos; la prensa mexicana, con 8; la española, con dos ejemplos en cada uno de los periódicos seleccionados; y la ecuatoriana y la peruana, con una única aparición, respectivamente. No se ha podido documentar este tipo de titular en el diario chileno. Por lo tanto, es muy llamativa la proporción de los titulares «declaración - verbo de comunicación - declarante» en la prensa colombiana (un $77 \%$ respecto de todos los titulares de este tipo), a una distancia considerable del resto de periódicos.

En cuanto a los verbos de habla, se encuentra en este grupo, como es sabido, todo verbo que denote un comportamiento verbal cualquiera, que exprese la realización de un acto lingüístico, sea cual fuere su naturaleza. Por lo tanto, el dominio léxico de los verbos de habla constituye el área conceptual de la realización de actos lingüísticos de cualquier índole.

Como era esperable, el más empleado es el verbo decir con 57 ejemplos. Esperable porque este es un verbo imprescindible en las páginas de cualquier periódico, ya que en cualquier cita periodística lo más inmediato es trasladar al lector que " $x$ ha dicho $y »$, donde decir es el más descriptivo y neutro de todos los verbos posibles, al no presentar ninguna connotación ni aportar otro significado que no sea el de 'manifestar con palabras un pensamiento', es decir, el puro hecho de locución. Veamos algunos ejemplos:

(1) 'Es un enorme día para el Perú, dijo el presidente Alan García (El Tiempo, Colombia)

(2) 'La elección de Chávez fue muy importante, pero le llevará a reflexionar', dijo el ex presidente (La Nación, Argentina)

(3) Estoy dolida con Colombia, dijo Ingrid Betancourt en el inicio de la gira promocional de su libro (El Tiempo, Colombia)

(4) «No crean todo lo que dice Wikipedia», dice cofundador de este sitio de consulta (El Tiempo, Colombia) 
(5) Un conflicto con Estados Unidos sería una guerra 'sin límites', dice Presidente de Irán (El Tiempo, Colombia)

(6) Reducir IVA no impulsará consumo, dicen expertos (El Universal, México)

Sin embargo, este verbo, con ser el más abundante en términos absolutos, solo representa el $48,3 \%$ de todos los casos en los que un verbo de habla se sitúa tras la cita. Esto significa que el 51,7\% restante (esto es, los otros 61 títulos) presenta un verbo más específico, porque el periodista, a la hora de elaborar el titular, puede preguntarse qué hizo el declarante cuando habló (además de decir algo). Y la respuesta puede ser afirmó, reveló, aseguró, advirtió... o cualquiera de los muchos verbos que denotan el sentido global de una locución (su fuerza ilocucionaria, el modo de realización fónica, el valor de verdad o falsedad del enunciado secundario, entre muchas otras especificaciones al significado referencial básico ${ }^{6}$ ). Por ejemplo, calificar una acción de advertencia, como en el siguiente titular, es una interpretación que puede ser muy informativa, siempre y cuando resulte acertada:

(7) 'Hay una nueva forma de comunismo', advirtió Álvaro Uribe (El Tiempo, Colombia)

El problema estriba en que es el informador quien interpreta y decide la palabra que utilizará para designar el sentido de la intervención hablada y, al margen de la dificultad con que puede encontrarse a la hora de interpretar correctamente las palabras del protagonista de la información, nada impide que esa elección sea pura y dura estrategia, de manera que la traducción de un acto de habla en un verbo que lo describe se convierte en una de las operaciones de mayor eficacia para la orientación ideológica de lo transmitido por parte del periodista. Este hecho, obviamente, condiciona el modo como el receptor interpreta la noticia; en otras palabras, impone una determinada lectura, interesada muchas veces, al destinatario, quien, en principio, no ha presenciado el acto verbal referido.

Dicho esto, destacan en nuestro corpus, por su frecuencia de uso sobre todos los demás, dos verbos distintos de decir: afirmar, que aparece en 15 ocasiones, y asegurar, con 12 ocurrencias. Estos dos verbos declarativos no presentan, en realidad, diferencias relevantes, puesto que ambos implican cierto grado de certeza en lo dicho. En efecto, afirmar transmite la convicción con la que el agente verbal efectúa sus declaraciones, mientras que asegurar implica también el compromiso por parte de la persona que hace la declaración de que lo que afirma es verdad. Por lo tanto, se trata de un alcance semántico que no posee el verbo decir, y así, aunque podrían reemplazarse por este verbo, decir no cubriría exactamente el mismo sentido que presentan afirmar y asegurar en ejemplos como estos:

${ }^{6}$ Todos estos verbos se distribuyen a lo largo de un 'continuum' de subjetividad (Kerbrat-Orecchioni (1980). 
(8) 'Fue una decisión desproporcionada', afirmó Bernardo Moreno (El Tiempo, Colombia)

(9) 'Ciberataques son una cuestión de vida o muerte', afirmó uno de los 'ciberforenses' más reconocidos del mundo (El Tiempo, Colombia)

(10) 'Los Kirchner acorralan a la prensa argentina', afirmó El País (La Nación, Argentina)

(11) Byron Moreno solicitó asistencia psicológica en cárcel, afirma Cónsul (El Universo, Ecuador)

(12) 'Nadie puede ser obligado a aceptar el aborto', aseguró el Procurador (El Tiempo, Colombia)

(13) Viagra no tendría efectos en más de la mitad de los casos, asegura especialista (El Tiempo, Colombia)

(14) Dios no es el creador del universo, aseguró el astrofísico Stephen Hawking (El Tiempo, Colombia)

(15) Israel 'desaparecerá para siempre' si ataca a Irán, asegura ministro iraní de Defensa (El Tiempo, Colombia)

La nómina de verbos diferentes de decir es, por orden decreciente, la siguiente: revelar (8 casos); advertir (6); anunciar (3); alertar (2), estimar (2) e informar (2); y, por último, con una sola aparición se han registrado los verbos agregar, reiterar, proponer, declarar, manifestar, denunciar, acusar, confesar, aconsejar, cuestionar y opinar. Menos acusar, todos los demás proceden de la prensa colombiana. Los siguientes testimonios tienen como objeto ejemplificar estas otras selecciones léxicas.

(16) 'Gran Bretaña viene a depredar nuestros recursos naturales', acusó la Presidenta (La Nación, Argentina)

(17) Alerta por embarazo en adolescentes, manifestó la representante del Fondo de Población de la ONU (El Tiempo, Colombia)

(18) Bebés que toman biberón corren más riesgos de ser obesos, revela estudio (El Tiempo, Colombia)

(19) Cuenta de Hugo Chávez en Twitter fue víctima de 'hacker': denuncian autoridades (El Tiempo, Colombia)

(20) Rafael Correa visitará Colombia en mayo, anunció embajador (El Tiempo, Colombia)

(21) Crece el riesgo de atentados en Francia, advierte el gobierno (El Tiempo, Colombia)

(22) 40 jóvenes entre los 10 y 29 años mueren al día de forma violenta en Europa, alerta la OMS (El Tiempo, Colombia)

(23) 'Lloré al verlo gritando de dolor', confesó colombiano que lesionó a jugador de Oriente Petrolero (El Tiempo, Colombia) 
La elección de estos verbos de habla y no de los anteriores, por ejemplo, responde, según Gutiérrez Ordóñez (1986: 28), a la intención de L1 de explicitar la fuerza ilocucionaria del acto de habla de L2, lo que evidencia una ideología subyacente.

A la vista del listado anterior de verbos de habla presentes en el corpus manejado, hay que concluir que, si bien el área conceptual de la realización de actos lingüísticos está cubierta por un vasto inventario de verbos, lo cierto es que el dominio léxico de dicha área está muy poco representado en este tipo de titulares, puesto que en nuestro corpus se ha visto reducido a 20 verbos, de los cuales, además, 11 tienen una representación mínima. Por otra parte, predominan los verbos que, aunque ciertamente añaden especificaciones diversas a su significado referencial básico, manifiestan la intención prioritaria de transmitir algo, de trasladar una información a otra persona.

A continuación, se presta atención a la forma de aludir al locutor secundario, que ocupa la posición de sujeto gramatical (situado, como sabemos, en último lugar en estos titulares). En relación con el grado de exactitud con que L1 alude a L2, es decir, al agente del acto verbal referido, existen cuatro formas de aludir a L2 (Nadal Palazón, 2009: 42): el locutor es mencionado de manera concreta y específica; opera una sinécdoque generalizante (donde L2 se halla representado por medio de una entidad de la cual forma parte); el locutor es aludido de manera inespecífica; o bien el locutor no es mencionado. Se puede hablar de sujetos determinados en los dos primeros casos, aquellos que L1 considera dignos de mención específica, y de sujetos indeterminados en los dos últimos, en donde la importancia que L1 otorga a L2 es, por supuesto, menor que en los casos anteriores, ya que ni siquiera se mencionan sus nombres.

En lo concerniente a titulares con verbo subordinante expreso, se registran $72,9 \%$ de ejemplos con semantismo propio donde el locutor es mencionado de manera concreta y específica, y 4,6\% de sinécdoque generalizante. Así, el total de sujetos determinados para los titulares estudiados en este apartado es de 77,5\%.

Los siguientes ejemplos ilustran la primera variante: los de semantismo propio, es decir, aquellos donde existe una correferencia transparente y simétrica:

(24) 'Si algo me pasa, mi amor infinito por la patria', dijo Rafael Correa desde el hospital (El Tiempo, Colombia)

(25) 'Esta es una civilización en declive', afirma Lester Brown (El Tiempo, Colombia)

Es frecuente también que aparezca otro tipo de información identificadora, sin mención del nombre del locutor, como en los títulos que se reproducen a continuación:

(26) 'Nos iremos del país dentro de tres días', dice la mujer del ex dictador de Haití (El País, España)

(27) Rafael Correa considera la opción de disolver el Congreso de Ecuador, dice su ministra de Política (El Tiempo, Colombia)

(28) 'Habrá cámaras en 198 colegios', anunció el secretario de Educación (El Tiempo, Colombia) 
En cuanto a la segunda variante de sujeto determinado señalada, hay que decir que «aunque toda sinécdoque generalizante produce, por definición, un efecto de inexactitud, debe tenerse en cuenta que [...] la entidad general siempre es específica. " (Nadal Palazón, 2009: 46) La inexactitud únicamente se presenta al establecer la correferencia con L2, que en el titular no aparece. Por ejemplo, en el siguiente titular, OMS (sigla de Organización Mundial de la Salud) es el sujeto gramatical del enunciado, pero, obviamente, no es el agente del proceso, sino que se trata de la institución a la que pertenece el agente real, que no está mencionado en el título:

(29) 40 jóvenes entre los 10 y 29 años mueren al día de forma violenta en Europa, alerta la OMS (El Tiempo, Colombia)

Otros ejemplos son:

(30) Juan Pablo II será beatificado el primero de mayo, anunció el Vaticano (El Tiempo, Colombia)

(31) 'Óscar Sevilla nos asegura que es inocente de dopaje', advirtió equipo del ciclista español (El Tiempo, Colombia)

Como ya hemos adelantado, tanto en estos ejemplos de sinécdoque generalizante, como en los anteriores, con un semantismo propio y una correferencia transparente, el periodista considera los sujetos dignos de mención específica. Ahora bien, como explica Nadal Palazón (2009: 42-43), la importancia conferida por L1 a L2 es mayor en los casos de sinécdoque generalizante que en los de semantismo propio. En efecto, si bien aludir a alguien por su nombre ya implica concederle un valor destacado, hacerlo por medio del todo al que pertenece apunta a un estatuto preponderante en la escala de valores de L1. La distribución de frecuencias de uso en nuestro corpus confirma que son menos los declarantes dignos de mención generalizante, coincidiendo con los datos que ofrece este investigador para la prensa mexicana.

Por otra parte, cabe la posibilidad de que se aluda al autor de las declaraciones de manera inespecífica, por medio de un sujeto indeterminado o por un sujeto tácito, lo que ocurre en el $22,5 \%$ de los titulares con verbo subordinante expreso. De ellos, un $20,1 \%$ presentan sujeto explícito indeterminado, lo que supone un L2 más importante que el aludido por medio de un sujeto tácito en una oración impersonal, ya que el agente, en los títulos con sujeto explícito indeterminado, está representado siquiera por una frase nominal, aunque imprecisa (Nadal Palazón, 2009: 43). En este punto hay que destacar que, junto a ejemplos en los que aparece un sujeto indeterminado como funcionario o diputada, con el rasgo [+ humano], también puede aparecer un sujeto no personal, porque, como explica Maldonado (1991:48), los verbos de habla efectivamente son verbos activos, es decir, exigen un agente humano, ya que designan una de las actividades más específicas de los seres humanos, pero en usos metafóricos puede aparecer un agente [- humano] en función de sujeto. En este caso, los verbos más empleados en nuestro corpus son los verbos menos marcados o menos subjetivos (por supuesto, decir). Se reproducen ejemplos de uno y otro tipo: 
(32) Grave, negar feminicidios, advierte senadora (El Tiempo, Colombia)

(33) 'Los dinosaurios siguen viviendo entre nosotros', dice paleontólogo (El Tiempo, Colombia)

(34) Dormir refuerza la memoria, dice estudio (El Universo, Ecuador)

(35) 'Maten al presidente', dice supuesta grabación de policías de Ecuador (El Tiempo, Colombia)

(36) Los ateos saben más de religión que los creyentes, revela encuesta hecha en EE.UU (El Tiempo, Colombia)

(37) El amor al dinero y al placer erótico estimulan zonas diferentes del cerebro, dice estudio (El Tiempo, Colombia)

Los sujetos léxicos no humanos están asociados con procesos de omisión del locutor secundario, es decir, con mecanismos lingüísticos empleados por L1 para no mencionar a L2, lo que responde a una pérdida del interés informativo por el agente del proceso.

Finalmente, en tres titulares (con el porcentaje más bajo de los correspondientes a este apartado: el 2,4\%) el sujeto ni siquiera es mencionado. En estos casos de sujeto tácito, la forma flexiva de tercera persona del plural, indicadora de una oración impersonal, permite reconocer un sujeto gramatical pero inespecífico. Los siguientes titulares son todos los testimonios del corpus que pueden ser clasificados en este grupo, todos ellos procedentes, como se puede ver, de la prensa mexicana:

(38) 'El Chapo' liderará tráfico de drogas en 2011, estiman (El Universal, México)

(39) Cárteles, un ejemplo de insurgencia, alertan (El Universal, México)

(40) Aniston quiere tener un bebé este año, aseguran (El Universal, México)

Ahora bien, el uso de estas estructuras sin sujeto gramatical propiamente dicho o cuyo sujeto aparece indicado únicamente en los morfemas de persona y número del verbo no encuentra su motivación en un desconocimiento del agente, ya que en la mayoría de los casos el contexto proporciona los datos que en el encabezado se evitan, sino en razones ideológicas de diversa índole. Lógicamente, estas razones varían según la circunstancias de la enunciación: la economía lingüística, la naturaleza del hecho verbal o el desconocimiento de información importante. Sin embargo, la motivación más habitual es la ideología de L1. En este sentido, y siguiendo el parecer de Nadal Palazón (2009: 54), podemos hablar de dos causas habituales: considerar la mención de L2 irrelevante desde el punto de vista informativo, o bien juzgarla contraria a los intereses de la organización editorial. En cualquier caso, el decidir cuál información se calla y cuál no es, de acuerdo con Van Dijk (2003), señal inequívoca de ideología subyacente.

En palabras de Nadal Palazón (2009: 43),

de acuerdo con el grado de importancia que los valores ideológicos asignan a L2 [el enunciador secundario], las cuatro estrategias se distribuyen a lo largo de un continuum, en cuyos extremos se hallan la sinécdoque generalizante y el sujeto tácito. 
Dicha generalización puede representarse de la siguiente manera: sujeto explícito determinado con sinécdoque generalizante - sujeto explícito determinado con semantismo propio - sujeto explícito indeterminado - sujeto tácito.

Por lo tanto, la ideología subyacente de la que habla Van Dijk (2003: 60-61) condiciona el procedimiento utilizado para aludir a L2, en el sentido de que la manera de realizar la atribución de las palabras de la cita evidencia claramente la ideología del locutor primario (en este caso, el periodista) en cuanto a la importancia específica del agente de la enunciación secundaria.

\subsection{Titulares del tipo «declaración - declarante» con verbo de habla elidido}

Seguidamente se examina la otra posibilidad anunciada: aquellos titulares de actos de habla del tipo «declaración - signo de puntuación - declarante» con verbo elidido. Como marcas de elipsis del verbo de habla, estos titulares presentan invariablemente los dos puntos, que indican gráficamente la yuxtaposición. Gracias a este procedimiento, con el que en ocasiones se economiza también algún que otro elemento gramatical, se produce lo que Alarcos Llorach (1977: 142) ha dado en llamar «bimembración expresiva», es decir, el proceso que genera una configuración lingüística donde tema y rema se hallan aislados. Se trata, como se ha señalado en muchas ocasiones, de una estructura lingüística propia de este espacio periodístico, un uso discursivo de los titulares difícilmente observable en otras situaciones de habla. Aun así, esta elipsis del verbo de habla no puede sorprender, si tenemos en cuenta la restricción del espacio disponible en la titulación periodística. Además, parece que dicha ausencia no implica confusión ni ambigüedad ninguna para el receptor, pues en teoría a este le resulta fácil reproducir el verbo elidido.

Asunción Escribano (2009: 13), en su estudio sobre las voces del texto como recurso persuasivo, denomina a este tipo de titular «cita directa bimembre», porque en esta situación aparecen enfrentados gráficamente el responsable de la cita y sus declaraciones; pero esta autora, al centrarse únicamente en la prensa española peninsular, solo tiene en cuenta el esquema: «declarante - dos puntos - declaración», porque en esta, considerando los datos disponibles, que nuestro corpus ha confirmado, es el único posible. Sin embargo, en la prensa hispanoamericana, concretamente en la prensa colombiana y mexicana, puede figurar el orden inverso: «declaración - dos puntos - declarante». Esta ordenación, según los datos de Romero Álvarez (2007: 637) sobre la sintaxis periodística de los titulares de la ciudad de México, supone el 65\% frente a la otra posibilidad. Nadal Palazón (2009: 45), por su parte, también destaca este fenómeno en la prensa mexicana; y así, del total de titulares con verbo subordinante elidido, señala que el $87,2 \%$ presenta la estructura «declaración - dos puntos declarante».

Gutiérrez Ordóñez (1986: 28) apunta que la elipsis se efectúa únicamente cuando se trata de «verbos semánticamente no marcados frente a aquellos otros que hacen 
referencia a un tipo de acto de habla concreto», lo que permite su fácil reconstrucción. A este respecto, Nadal Palazón (2009: 196) sostiene que la elisión del verbo no responde siempre a la existencia de un verbo de habla semánticamente inespecífico, sino que, sin negar las incuestionables necesidades de economía del discurso de los titulares, existe la posibilidad, según explica este investigador, de que el periodista busque deliberadamente ocultar su interpretación del acto de habla ajeno, en perjuicio, por supuesto, de la informatividad del texto. Lo explica de la siguiente manera:

La elisión de verbos de habla responde, al menos en parte, a pretensiones de neutralidad aparente. Dado que la interpretación del acto de habla ajeno recae, en buena medida, en los verbos de habla, podemos suponer que la omisión de éstos se debe, además de a las necesidades económicas propias del género discursivo, a una intención de no expresar la lectura que L1 hace del hecho lingüístico noticioso; ello contribuye a la configuración de una imagen discursiva de locutor neutral y sobrio.

Para este investigador, en fin, la omisión de verbos de fácil recuperación, y más bien inespecíficos, se debe a la tensión entre interés y relevancia a que está sujeta la enunciación de encabezados periodísticos, la cual, al decir de Nadal Palazón (2009: 44), «busca un equilibrio entre economía e informatividad».

El número de titulares de este tipo («declaración - dos puntos - declarante») en el corpus considerado para este trabajo es de 110 , lo que representa el $48,2 \%$ respecto del total de titulares examinados en esta ocasión. Esta cifra se reparte entre los periódicos $E l$ Universal de México (con 30 ejemplos) y El Tiempo de Colombia (con 80). Luego el porcentaje de frecuencia de uso más alto de este segundo tipo de titular corresponde, de nuevo, a la prensa colombiana.

En cuanto a la manera de aludir al sujeto, del conjunto total de titulares con verbo de habla elidido, un $62,7 \%$ de los casos presenta sujeto explícito determinado, como se pone de manifiesto en los siguientes enunciados:

(41) 'El resultado fue muy amplio': Eduardo Lara, técnico de Colombia (El Tiempo, Colombia)

(42) La gente pide otro canal de TV: ministro de Tecnologías de la Información y las Telecomunicaciones (El Tiempo, Colombia)

(43) Avances militares de China desafían a EE.UU.: Secretario de Defensa (El Tiempo, Colombia)

(44) Pensar diferente no es traición: Ortega (El Universal, México)

(45) 'No nos vamos a dejar pisar más': Márquez (El Universal, México)

Asimismo, se han documentado titulares (el 10\%) que presentan un sujeto explícito determinado de sinécdoque generalizante, como en:

(46) Declaraciones del presidente de Irán sobre atentado del 11-S son inaceptables: Unión Europea (El Tiempo, Colombia) 
(47) Norma de hace 153 años que 'empeñaba' niños es inaplicable: Corte (El Tiempo, Colombia)

(48) Retribución irá a la par con el crecimiento agrícola: Gobierno (El Tiempo, Colombia)

En conjunto, los casos de sujeto determinado han descendido a un $72,7 \%$, lo que implica, naturalmente, que los casos con sujeto indeterminado han aumentado en este tipo de titular de acto de habla sin verbo expreso. En concreto, los titulares que cuentan con sujeto explícito indeterminado con el sema categorial [+ humano] o bien sin él, presentan un porcentaje de aparición del $27,3 \%$, cifra que engloba entonces los casos de entidades humanas y no humanas que concuerdan con el verbo.

He aquí algunos ejemplos de titulares con sujeto con el sema categorial [+ humano]:

(49) Beatificación de Juan Pablo II, el camino a su santificación: biógrafo (El Tiempo, Colombia)

(50) Foto de Bravo y Olivares, momento de euforia: senadora (El Universal, México)

No obstante, el sintagma nominal que funciona como sujeto designa entidades no humanas en más de la mitad de los casos con sujeto indeterminado. Veamos unos ejemplos:

(51) Analgésicos de venta libre podría aumentar riesgo cardíaco: estudio (El Tiempo, Colombia)

(52) Gen es el responsable de migrañas: estudio (El Universal, México)

(53) 'Sin libre expresión no hay democracia': portadas de prensa bolivianas (El Tiempo, Colombia)

Hay que insistir en que el periodista asigna mayor o menor importancia a los locutores secundarios de acuerdo con el grado de detalle con el que los alude: o de manera concreta y específica o bien de modo general o inespecífico ${ }^{7}$.

\section{Conclusiones}

El titular de acto de habla con el orden declaración - declarante no está repartido de manera uniforme en nuestro corpus. Mientras que en la prensa colombiana y la mexicana es posible documentar este tipo de titulación, en el resto de periódicos analizados su presencia es escasa o, en el caso de la prensa chilena, inexistente. Hay que llamar la atención sobre el hecho de que sea la prensa colombiana la que proporcione el mayor número de ejemplos de este tipo, ya que esta ordenación, en la que el relieve

\footnotetext{
${ }^{7}$ Obviamente, al no presentar verbo estos titulares, si no se menciona el declarante (opción que sí era posible en el otro tipo de titular analizado, como hemos visto), estamos ante un titular conformado únicamente por la cita, cuyo estudio y análisis no tiene cabida dentro de los límites que nos hemos impuesto en este trabajo.
} 
focal recae en las declaraciones, ha sido señalada como característica de la prensa mexicana, lo que tiene que ver con el hecho de que esta haya sido más estudiada que la colombiana. Sin embargo, en nuestro corpus, es el periódico colombiano el que muestra la frecuencia de aparición más alta de este titular, tanto con verbo expreso como sin él.

Los verbos de habla están muy poco representados en estos titulares y se escogen, por lo general, los que en su caracterización semántica tienen como rasgo más relevante 'expresar una aserción' e implican, por lo tanto, una menor subjetividad por parte del locutor que refiere. Especialmente se selecciona este tipo de verbos de habla no marcados para acompañar a sujetos indeterminados con el rasgo [- humano], mientras que en los casos de sujeto determinado podemos encontrar verbos más marcados o subjetivos.

En cuanto a la manera de aludir al sujeto, tanto en los titulares con verbo expreso como con verbo elidido, abundan los titulares con sujeto determinado, pero se observa un aumento de ocurrencias con sujeto indeterminado, en especial con sujeto [humano] en los casos de titulares sin verbo de habla expreso, lo que implica que en estos títulos sin verbo se tiende a ocultar o a restar importancia a L1.

En definitiva, el análisis efectuado nos ha llevado a descubrir ciertas particularidades del titular con el orden declaración - declarante, pero más allá de esto, ha puesto de manifiesto que las diferentes codificaciones lingüísticas de este tipo de titular responden a estrategias argumentativas y persuasivas que pueden constituir buenas pistas para el estudio de la orientación ideológica de los discursos, porque el omitir u ocultar información así como expresarla con mayor o menor detalle revela una estrategia diferente pensada y llevada a la práctica por el locutor primario, quien, a pesar de las pretensiones de objetividad derivadas de su profesión, no duda en adaptar sus puntos de vista y sus valores a las exigencias de las organizaciones informativas.

Recibido: 29.01.2014

Aceptado: 20.06.2014

\section{Referencias bibliográficas}

Alarcos Llorach, E. (1977): «Lenguaje de los titulares». En Lázaro Carreter, F. (ed.): Lenguaje en periodismo escrito. Madrid, Fundación Juan March, págs. 125-148.

Bell, A. (1991): The Language of the News Media. Oxford, Blackwell.

Díaz Noci, J. (2002): El discurso digital. Bilbao, Universidad del País Vasco.

Escribano, A. (2009): Las voces del texto como recurso persuasivo. Madrid, Arco Libros.

Fairclough, N. (1995): Media Discourse. London, Edward Arnold.

Gómez Mompart, J. L. (1982): Los titulares en prensa, Barcelona, Mitre.

Gutiérrez Ordóñez, S. (1986): «Observaciones sobre el estilo directo en español». Estudios Humanísticos. Filología, 8, págs. 23-38. 
Gutiérrez Ordóñez, S. (1997): Comentario pragmático de textos polifónicos. Madrid, Arco Libros.

Hodge, R. y G. Kress (1993): Language as Ideology. New York, Routledge.

Kerbrat-Orecchioni, C. (1980): L'énonciation. De la subjectivité dans le langage. París, Librairie Armand Colin.

López Hidalgo, A. (2001): El titular. Manual de titulación periodística. Sevilla, Comunicación Social.

Maldonado, C. (1991): Discurso directo y discurso indirecto. Madrid, Taurus Universitaria.

Mathesius, V. (1975): A Functional Analysis of Presente Day English on a General Linguistic Basis. Praga, Academia.

Nadal Palazón, J. (2009): El discurso ajeno en los titulares de la prensa mexicana. México, UNAM.

Núñez Ladevéze, L. (1991): Manual para periodismo. Veinte lecciones sobre el contexto, el lenguaje y el texto de la información. Barcelona, Ariel.

Núñez Ladevéze, L. (1995): Introducción al periodismo escrito. Barcelona, Ariel.

Rodrigo Alsina, M. (1989): La construcción de la noticia. Barcelona, Paidós.

Romero Álvarez. M. de L. (2000): «El relato de palabras como recurso de credibilidad en el relato periodístico». En A. Gimate Welsh (ed.): Ensayos semióticos. Dominios, modelos y miradas desde el cruce de la naturaleza y la cultura. México, Benemérita Universidad Autónoma de Puebla / Porrúa / Asociación Mexicana de Estudios Semióticos, págs. 97 106.

Romero Álvarez, M. de L. (2007): «Sintaxis periodística de los titulares en los diarios de la ciudad de México». En Mariscal, B. y T. Miaja de la Peña (coords): Actas del XV Congreso de la Asociación Internacional de Hispanistas «Las dos orillas». México, El colegio de México, vol. 4, págs. 635-644.

Salaverría, R. (2005): Redacción periodística en Internet. Pamplona, Eunsa.

Santander Molina, P. (2003): "Acceso y discurso referido en el periodismo televisivo». Revista iberoamericana de discurso y sociedad, 4 (2), págs. 9-32.

Van Dijk, T. A. (1990): La noticia como discurso. Barcelona, Paidós.

Van Dijk, T. A. (2003): Ideología y discurso. Barcelona, Ariel.

Waugh, L. R. (1995): «Reported Speech in Journalistic Discourse: The Relation of Function and Text». Text, 15, 1, págs. 129-173.

Zorrilla Barroso, J. M. (2002): El titular de la noticia: estudio de los titulares informativos en los diarios de difusión nacional. Madrid, Universidad Complutense. 